\title{
Issues of water in India and the Health Capability Paradigm
}

\author{
Rhyddhi Chakraborty* \\ Department of Philosophy and Global Health, American University of Sovereign Nations, Scottsdale, AZ 85250, USA
}

\begin{abstract}
Water, a finite natural resource, is vital for the generation, sustenance and flourishing of all life forms. Rampant use and misuse of water make it a depleting natural resource. Consequently, conflicts and stresses have emerged involving the availability, accessibility, and quality of water. The shortage of water has also contributed to the spread of waterborne diseases. The crisis of availability and accessibility of quality water and the emergence and prevalence of these waterborne diseases have pushed some groups and individuals to suffer more than others. This disparate impact has contributed to inequities - especially health inequities - by failing to prevent the avoidable impacts of water shortage and waterborne disease on the health of individuals and groups. Considering this fact, the central argument of this paper is that water-related inequities are actually inequities caused at the level of health capabilities of groups and individuals. To address such inequities, this paper suggests that there is a need for a new foundation of water ethics because the existing frameworks fail to capture and address water-related inequities that are caused at the level of health capabilities. With a focus on India, this paper then argues that the new water ethics can be founded on Jennifer Prah Ruger's social justice theory of the 'Health Capability Paradigm (HCP)'. This paper then identifies and recommends some desirable changes to be made in the implementation of Indian water policy.
\end{abstract}

KEY WORDS: Ethics $\cdot$ Health Capability $\cdot$ India $\cdot$ Social Justice $\cdot$ Water

\section{INTRODUCTION}

The element of water can be conceived as an entity, an idea, a source of power, wealth, inspiration, joy and even a source of misery and woes for humans (Johnston 2012). This paper focuses on the misery and woes that water-related issues bring to the health and lives of humans. The rampant use and misuse of water has made it a depleting natural resource. Scarcity of water, reduced access to clean and safe water, and water-related mishaps loom large for the human population (Liu et al. 2011, Johnston 2012, Venkatraman 2015) and have given rise to conflicts and stresses between countries, between classes and between people. The crisis of availability, accessibility, and quality of clean water has also contributed to the spread of waterborne diseases. This crisis and the

\footnotetext{
${ }^{*}$ Corresponding author: rhyddhi_414@yahoo.co.in
}

emergence and prevalence of these waterborne diseases have caused some groups and individuals to suffer more than others in terms of maintaining their health status. These individuals typically reside either in a specific geographical location, or belong to a specific class or section of society (Liu et al. 2011). These groups or individuals, because they are more negatively affected than others by a water crisis and waterborne diseases, are then differentiated from more prosperous people by an unfair gap made at the societal level. Such a gap causes inequity in society. This imbalance, this paper contends, is actually caused at the level of the health capability to avoid waterborne health inequities. To address such inequities at the level of health capabilities, this paper argues for the inclusion of ethics in water management and use policies. The theory of the 'Health Capability Para-

๑ The author 2017. Open Access under Creative Commons by Attribution Licence. Use, distribution and reproduction are unrestricted. Authors and original publication must be credited. 
digm' (HCP) (Ruger 2009) is a relevant social justice theory on which to base the argument at hand, since the existing theories and frameworks of water ethics fail to demonstrate that waterborne inequities are actually caused at the level of the health capabilities of groups and individuals. With a specific focus on Indian water policy and initiatives, and borrowing some concepts from the $\mathrm{HCP}$, this paper suggests that Indian water policy and some of its major initiatives should undergo changes - both at the level of vision and in implementation - to address these issues of inequity.

\section{THE ETHICAL CONSIDERATION OF WATER}

An extensive literature review on water ethics portrays a dichotomy in the need for better water management and use (Selborne 2000, Acreman 2004); the discussion has always been on how better to distribute water as a resource, as a common good, and on the dependence and interdependence of water (as a natural resource) and human beings (Macer 1994). In-depth reviews suggest that the need for ethics in water management and use are presented only when there are disasters, scarcity, pollution or when water has become a potential source of conflict (Selborne 2000). In spite of advice that suggests giving due significance to water, by and large, water is completely overlooked as a potential source of contention and stress, and the need for ethics has been overlooked in favor of better water use and management. For instance, the Food and Agriculture Organization (FAO) has reported that since 1945, around 300 treaties dealing with water management or distributions in international basins have been consulted to deal with irreconcilable circumstances (FAO 2016). However, none of the various and extensive databases on the causes of conflicts have indicated water as the primary cause of these clashes, and thus did not delve into the need for ethics in water management and use.

A review of the need for ethics in water management and use reveals that ethics have long been too low on the public policy agenda. The need for such inclusion usually follows an experience of changes in weather patterns and climate. To keep pace with such experiential lessons, the history of water policies has evolved from 'command-and-control' to a more ecological approach. Supporting such change, and to clarify management goals to promote more sustainable practices, some researchers point out the dire need to bring in the topic of values and ethics into the water policy discourse (Groenfeldt 2010). To help the countries with their sustainable water practices and policies, global 'think tanks' such as the United Nations Educational, Scientific and Cultural Organization (UNESCO) promote key ethical principles of equity, vicinity, frugality, quantification, transaction, user-pay and participation. In spite of such available guidance, UNESCO has observed gaps in the understanding and approaches to link the extensive agreements on water sharing, in consumption patterns within and between countries, and even in the governance of water (Liu et al. 2011).

The requirement for water ethics has also been proposed as a way to manage water-related inequity issues. It has been anticipated that in the 21st century, one-fourth of the total population or $33 \%$ of the population in developing nations will encounter a serious water shortage. Moreover, it is estimated that water will have its single greatest impact on the poor, especially through the production of the kinds of food they consume (Seckler et al. 1999). To save the lives of these people, a group of researchers is driving the need for justice in water ethics. They specify that justice in water allocation, governance, use, integration and management can enable better life security, food security, and can also provide opportunities for the right to access safe drinking water and adequate sanitation (Water Ethics Network 2015). Ethical guidance to ensure water distribution and access, they emphasize, is to be girded with the underlying vision of social justice. It is through the availability of water to all, through the right to access to safe drinking water and sanitation, that the right to health and life can be ensured.

The need for social justice for water ethics has also been emphasized as a way to deal with the issues of water stress and conflicts between countries and states, as well as among people. Stress and conflict about water arise mainly due to water governance and sharing. To cite an example; in May 2015, in a village about $400 \mathrm{~km}$ from Bhopal, Madhya Pradesh, India, the 'untouchable' lower caste Dalits were banned from accessing the only available hand-operated public bore well by the upper caste tribal members of the village. Consequently, being forced to drink contaminated water from a disused well, children of that Dalit community became sick and diseased (PTI 2015). The conflicts from such cases have highlighted the deprivation of the basic right to access water, liberty of utilization of available water, rights to available groundwater as well as surface water, and also rights to avoid caste-class distinction (Asthana \& Shukla 2014). This kind of deprivation of 
rights and liberties shows the undue advantage of some over others and establishes the need for ethics of social justice to provide a just and fair share of available water. Social justice has also been justified as a necessary framework for water ethics with a direct focus on the unavailability of safe water and its impacts on human health. Safe water and basic sanitation are considered as the major determinants of human health and development. However, a few groups and individuals have been denied these basic needs and made to suffer more than others. For example, in 2014, the WHO reported increased cases of cholera in countries where there is inadequate access to clean water and sanitation. In that year, $55 \%$ of cholera cases were from Africa, 30\% from Asia, and $15 \%$ from the Americas (WHO 2016b). As indicated by the World Health Organization (WHO), the absence of safe drinking water and poor sanitation adds to around $80 \%$ of transmittable sicknesses, especially among children. The WHO reports that in developing countries each year 1 in every 10 children dies before the age of 5 because of water-related diarrhoeal disease (WHO 2016a). Despite the availability of simple effective treatment against these diseases, some poeple and children suffer because of access to unsafe water.

While children suffer more than adults from avoidable waterborne diseases, women suffer more than others in fetching water. When water sources are a long way from their homes, are unclean, or in short supply, women are the first to experience the ill effects of the subsequent weariness and illness. For the benefit of their families, women must walk miles, carry overwhelming weights, wait for a long time and even pay extreme costs - and even then may not have access to water. This striving for the sake of fundamental need of water leaves these women with 2 choices: 'certain death without water or possible death from illness' (Water.org 2017a). In developing countries, when children or other family members are sick because of preventable waterborne diseases, women must care for those who are ill, thus having less time to care for other family members, to support their children's schooling, to work in the field and do other work, and to take care of themselves (Rodda 1991, Prüss-Üstün \& Corvalán 2006). Shortage of water also hinders the dignity and privacy of girls and women because they are affected by the process of improper sanitation and hygiene. In many countries, many girls are still made to drop out from schools when they reach puberty due to the lack of privacy of female toilets in the institutions (www.water.org). The lives of women are also mostly at risk due to waterborne diseases. Trachoma, a water-hygiene disease that causes blindness, is hyper-endemic in many of the poorest and most rural areas of 51 countries of Africa, Asia, Central, South America, Australia, and the Middle East. Women of those region are blinded 2 to 3 times more often than men, probably due to their close contact with infected children and being more susceptible to greater frequency of infection (WHO 2015).

Summing up, accessibility to available water and utilization of water, specifically safe and clean water, helps one to sustain life. It also helps to avoid diseases and poor health, directly or indirectly. However, while this is a provision for some, many others especially people in developing countries, people of certain backgrounds, women and children-compromise their health and become sick because of little or no access to safe water, or due to exposure to contaminated water. As lack of access to, and utilization of, water hinders the chance of good health of some, it contributes to a health gap, technically known as health inequity. This inequity, being unjust and avoidable, demands ethical guidance-especially the guidance of social justice. This health inequity also causes insecurity, be it for social development, human development or to freedom from preventable disease and premature death. The issue, in spite of establishing the need for inclusion of social justice within the discourse of water ethics, however, has attracted little attention in the research literature. Consequently, this paper aims to investigate the issue with an emphasis on India.

\section{WATER AND INDIA}

India supports about $17 \%$ of the world's human population; however, it has only $4 \%$ of world water assets. The main source of water in India is precipitation and transboundary flows from the upper riparian countries (Chakraborty \& Mukhopadhyay 2014). However, leakage and inefficiencies in water management lead to nearly $50 \%$ wastage of usable water. In addition, the nation is comprised of 20 water units, including 14 river basins; however, there is a spatial imbalance in total water asset dispersion. For example, the Ganges-Brahmaputra-Meghna basin covers $34 \%$ of the country's area and contributes around $59 \%$ of the nation's water assets. The west streaming waterways towards the Indus cover $10 \%$ of the region and contribute $4 \%$ of the water resources. The remaining $56 \%$ of the area contributes about $37 \%$ to the runoff (FAO 2016). 
The water-related issues on the Indian subcontinent are worsening. India is coping with the dangers of environmental change, which could complicate the pattern of availability of water resources, including changes in the pattern and intensity of rainfall, glacial melt resulting in altered river flows, changes in ground water recharge, more severe floods and droughts, saltwater intrusion into coastal aquifers and deterioration of the quality of drinking water (Planning Commission 2013). Some of the significant issues encompassing water in India are detailed below.

\section{Ground water over-extraction}

India is the largest and fastest growing user of ground water in the world. Over the last 3 decades, ground water has been the main source of waterfor both drinking and irrigation - thereby being a major support of water security in the country. Over the last 4 decades, around $84 \%$ of the total addition to the net irrigated area has come from ground water, implying the dependence of many industries upon ground water. However, ground water is being exploited unsustainably (Planning Commission 2013), leading to a 'water gap' of about $50 \%$ between demand and supply (Planning Commission 2013). The ground water level in the country is declining at an average rate of $10 \mathrm{~cm}$ per year, leading to severe water scarcity in some parts. For instance, the state of Maharashtra (a western state) has been facing severe drought and water crisis during the summers for several years. Mumbai, the state capital, faced a $15 \%$ water deficit leading to water cuts to residential areas in 2015 (Venkatraman 2015). The over-extraction and decline of ground water, combined with climate change impacts, is leading to detrimental consequences for society. For instance, in 2016, as a result of the El Niño effect, severe drought and water shortages occurred in the Gangetic plain and even in the Himalayan foothills (Tiwari 2016, Menon 2016). The drought, in addition to causing water scarcity, also prompted people to riot to access water, or to commit suicide because of debt and crop failures (Mohan 2016).

\section{Shrinking storage capacity}

A World Bank study pointed out that most of the peninsular river basins such as the Kaveri, Krishna and the Godavari, and the west-flowing rivers of the country such as the Narmada and Tapti have shrunk to the extent that they are unable to add any extra volume of water in their carrying capacities. Similar studies by the International Water Management Institute (IWMI) have shown that the southern rivers Krishna and Kaveri reached full or partial closures, and in the Krishna river basin, the storage capacities of large and medium reservoirs reached a total water yield, with virtually no water reaching the sea in low rainfall years. A concern has also been raised over the fact that the capture of excess water from the basin along with the evaporation of an additional 36 billion cubic metres (BCM) of water has changed the regional weather pattern, aggravated saline groundwater intrusion, and put the delicate wetlands estuarine environments important for the sustainability of aquatic habitats and fisheries and prevention of shore erosion - at risk. The lack of adequate environmental flows in the Krishna river, as the Government of India claims, has significantly aggravated water pollution problems in cities since domestic and industrial effluents can no longer be sufficiently diluted by flowing water (Planning Commission 2013).

\section{Water conflicts}

India faces both internal and external water conflicts. Repeatedly, sharing of Indus and Ganga water has been a major concern between India and Pakistan, and India and Bangladesh. Within the country, Krishna and Cauvery water disputes between the states of Tamil Nadu and Karnataka make headlines almost annually. A forum to discuss water conflicts and to delve into policy dialogues in India has determined that there are 128 areas of water conflict in the country, including equitable water usage, access allocation, water quality, sand mining, construction of dams and displacement and privatization (India Water Portal 2008).

\section{Waterborne diseases}

In spite of government efforts to combat waterborne diseases, they have continued to increase over the years in India. States such as Punjab, Haryana, Andhra Pradesh and Uttar Pradesh are often locations of malaria endemics because of waterlogging and seepage in the canal catchment areas. There are also surprising rates of Chikungunya, Filariasis and Kala-azar across the nation (Government of India 2014). The persistent problem of unclean water also contributes to childhood diseases (Planning Commis- 
sion 2013). According to World Bank estimates, waterborne diarrhea alone causes more than 1600 deaths daily, and $21 \%$ of communicable diseases in India are related to unsafe water, although access to drinking water has improved over the years (www.water. org). In addition, due to lack of sanitation, improper sewage disposal, dropping water levels and drying up of reservoirs during summer, there are increasing cases of water contamination with arsenic and fluoride, and bacterial contamination resulting in ill health (www.water.org).

\section{Disproportionate burden on some}

Scarcity of water affects rural India more than urban areas. The Government's 12th Five Year Plan (2012 to 2017; Planning Commission 2013) states that rural areas lag behind urban centers in accessing safe drinking water. The report also specifies that women, children, people of the tribal region and other socially and economically disadvantaged people bear most of the burden of the water crisis. In 2007, it was calculated that one-sixth of the life span of Indian rural women is dedicated to looking for water, which does not always result in certain supply or access. It has also been estimated that the national cost of women fetching water is 150 million women work days per year, which is equivalent to the national loss of income of 10 million Indian rupees (WSP 2007). A focus group study revealed that poor sanitation facilities and contaminated water have exposed women to otherwise preventable diseases and have increased their medical expenses (Victor 2006).

Beyond the risk of disease and death, scarcity of water also affects women's emotional and mental health in India. While inadequate sanitation puts people at greater risk of experiencing social stigma, emotional distress, and mental ill-health, scarcity of water also puts women at greater risk of abuse from family members. For instance, many women in India suffer abuse and humiliation from their husbands when they lack sufficient water to clean their homes (Wutich 2013). These facts and figures highlight that there is an unfair and unjust provision of availability, accessibility, supply, quality and use of water in the country. This often leads to conflicts: physical, emotional, social. Therefore, the water policy in India needs to have some ethical considerations to address these issues of unjust and unfair provision of safe water, security of the rights to water and health and lack of protection from preventable diseases. Otherwise, failure is caused at the level of provision, pro- tection is not ensured at the population level from preventable and avoidable diseases and an unjust health gap is caused at the individual and population level. This requires a survey on major water-related initiatives, policies and strategies in India, to determine the extent to which they acknowledge, recognize, and address these issues.

\section{WATER-RELATED INITIATIVES IN INDIA}

Implementing initiatives in water reform in India has been an age-old procedure. The following is a brief review of some of the major initiatives taken at the country level to resolve India's water-related issues.

\section{Central Ground Water Board}

The Central Ground Water Board (CGWB), established in 1970, is a subordinate office of the Government of India's Ministry of Water Resources, and is the National Apex Agency entrusted with the obligation to provide scientific input for the management, exploration, monitoring, assessment, augmentation and regulation of the ground water resources of the country. Major activities undertaken by the board include macro/micro-level ground water management studies, exploratory drilling programs, and monitoring of ground water levels and water quality through a network of ground water observation wells (CGWB 2015). However, when it comes to implementation of its goals and strategies, the board emphasizes more inter-sectoral and inter-ministerial management and coordination than giving importance to the issues of ground water management and its implications for the health of the people of the country.

\section{Integrated Watershed Management Program}

A national committee for Integrated Water Resource Management (IWRM) was set up and implemented in 1999. The objective of the program was to converge all repair, renovation and restoration projects within the IWMP to better treat the catchment areas along with the repair and renovation of the water body itself. However, this IWRM framework has been criticized for very serious difficulties in implementing solutions for the increasingly complex and interdependent issues and activities surrounding water in India (Biswas \& Tortajada 2010). It has also been 
pointed out that even after more than half a century of existence, this committee has failed to find a practical framework for integration of the various issues associated with water management in the country (Biswas 2008). Moreover, it has been found to be a random project, lacking a theoretical undergirding to address the issue of water-related disproportionate impacts on some groups.

\section{National Water Policy 2012}

The first National Water Policy was embraced in September 1987, revised by the National Water Resources Council in April 2002, and reviewed and updated in 2012. The objective of the National Water Policy (Government of India 2012) is to take cognizance of the existing water-related challenges, to propose a framework for the creation of a system of laws and institutions and to plan actions with a unified national perspective. According to the national water policy, because of the vital importance of water for human and animal life, for maintaining ecological balance, as well as economic and developmental activities of all kinds, and considering its increasing scarcity, the planning and management of this resource along with its optimal, economical, and equitable use have become a matter of the utmost urgency (Government of India 2012). The water laws in the country, based on the water policy, mention the impacts of the water crisis on health, and point out the need for social justice and equity for the allocation of water, but do not mention how the scarcity of water actually affects the ability of the people to cope with their environment, to avoid preventable diseases and premature death. Also, even with revisions, water laws in India continue to remain non-uniform, inconsistent and somewhat inadequate to deal with the complex situation characterized by scarcity, increased demand, and depletion of this renewable but limited resource.

\section{Water Laws in India}

There are many water-related laws in India, such as The Northern India Canal and Drainage Act, 1873, The Bengal Irrigation Act, 1876, Specific Relief Act, I of 1877, Interstate Water Disputes Act, 1956 and The Water (Prevention and Control of Pollution) Act, 1974. Laws such as the Ganga Action Plan (1986) are intended to rejuvenate and clean the rivers of India. There are also laws involving sanitation, protection of water as an environmental resource, ground water preservation, interstate river linkages and interstate water dispute prevention. However, as pointed out by various researchers, in spite of being numerous, the water-related laws in India lack clarity in how to use and manage water efficiently (George 2012). More recently, in 2014, the Right to Water has been ordered to be followed legally as an integral part of the Right to Life under Article 21 of the Indian Constitution, which safeguards the protection of life and personal liberty (HRWS 2016). In spite of this order, the scenario has not changed the fate of many people who are deprived of access to available water.

\section{National Water Mission}

The main objective of the National Water Mission is 'conservation of water, minimizing wastage and ensuring its more equitable distribution both across and within States through integrated water resources development and management' (MWR 2014a, p. 46). The mission identified its goals as follows: (1) to maintain an all-inclusive water database and assessment of the impacts of climate change on water resources, thereby making it available in the public domain; $_{\text {(2) }}$ to promote citizen and state actions for water conservation, augmentation, and preservation; (3) to focus attention on vulnerable areas including over-exploited areas; (4) to increase water use efficiency by $20 \%$, and (5) promotion of basin-level integrated water resource management (CMD 2011).

Acknowledging the grave impacts of climate change, and with concern about coping with climatic changes, the government has recommended respecting water rights (MWR 2014b). However, the rights here imply the rights of states to use a proportionate quantity of water, not the health rights of individuals as entitlements against the risks of unsafe water.

The Government of India, through its above-mentioned schemes and policies, has also attempted to provide due attention to the individuals and groups deprived of accessibility and availability of water. For instance, for fulfilling the commitments of the National Water Policy, the Government notifies that farmers' participation in various aspects of management of irrigation systems, particularly in water distribution, is to be considered. In addition, the Ministry of Water Resources has issued guidelines to States to consider the representation of women in the Water Users' Associations (WUAs) at all levels. As a result, many States have amended their Irrigation Acts or developed Specific Acts on Participatory Irrigation 
Management (MWR 2014a). These amendments and concerned actions imply the need for ethics of social justice to address the range of issues involving water in the country. However, it undermines the importance of the ethical concern for the need of protection of the health functionings and abilities from waterrelated escapable diseases and premature deaths.

\section{A SUITABLE COMPREHENSIVE FRAMEWORK OF SOCIAL JUSTICE}

In the domain of water ethics, especially within the context of social justice, there are recommended frameworks (Anand 2013, Wutich 2013) to establish links between the access to water and human capability. However, there is no such framework linking the impact of water on the capabilities of the individual. To establish such a relationship, this study has chosen to borrow the social justice theory of the HCP (Ruger 2009), whose focus is on the health of individuals and how different social and economic factors such as access to clean water affect the health capabilities of individuals and groups.

The HCP is gaining popularity, mainly for the reformation of the healthcare system, health policy and public health policies. In this paradigm, 'health capability' is a person's ability to be healthy; there is a special moral importance of health capability, which signifies more than the simple physiological health. J. P. Ruger, founder of the paradigm, defines it as '... the ability of individuals to achieve certain health functionings and the freedom to achieve those functionings' (Ruger 2009, p. 81). While health functionings are essentially the avoidance of disease, deformity, malnutrition, disability, and reaching normal life expectancies, in $\mathrm{HCP}$, it means the freedom of choice to pursue these functionings. However, the core freedom in the HCP is freedom from escapable diseases and premature death (conditioned by social, economic, political, and other factors) and in terms of health capability, it is the central health capability (Ruger 2009).

Apart from central health capability and health functionings, health agency, and shared health governance are the other core components of the paradigm. The health agency is the group or individual who has the ability to pursue valuable health goals and has the capacity to bring health effectively, having adequate health knowledge, effective decisionmaking abilities in health matters, self-health management, self-health regulation skills, etc. (Ruger 2009). With the health agency comes the individual responsibility of using healthcare, other societal resources, as well as conditions provided by society, and translating them into maximal levels of health functioning. So even if society guarantees equal access to (high quality) health care, individuals must exercise their health agency rights to translate these resources into maximal levels of health functioning (Ruger 2009). And health functionings involve collective societal obligations to ensure and enable the conditions to achieve good health. The concept of collective obligation takes us to the guiding concept of shared health governance - 'a construct in which individuals, providers, institutions work together to empower individuals and create an environment enabling all to be healthy' (Ruger 2009, p. 13). These health functionings and health agency are considered as proxies to determine the central health capability, as they are not directly observable and measurable (Ruger 2009). And HCP proposes that inequalities in health are actually inequities in these central health capabilities. The health inequities, consequently, deprive people of achieving good health - these deprivations Ruger calls shortfall inequalities, which stands for shortfalls of actual achievement from the optimal average. As a paradigm, this health capability proposes that the assessment of the effects of health care on individuals' health capability are to be done by examining health needs, health agency, and health norms and to be evaluated by the conceptual guidance of shared health governance. The quality of the health care system is to be evaluated by its ability to address functional impairments arising from injury or illness (Ruger 2009).

This study extends and justifies this social justice framework to the discourse of water ethics for the following reasons:

(1) Scarcity in the availability or supply of water and uneven distribution of water results in some people being more deprived than others in terms of accessing water. As a result of this deprivation, some groups suffer more than others by not being able to have what they value in their lives. For instance, when the availability of water affects farming and food security, it obstructs the opportunities of some not to exercise their choices, be it for occupation, food, health or life. And by doing so, it is the life capabilities of some that are affected. So also, when shortage of water drives a few people to utilize low quality or contaminated water, these groups or individuals are distinctly denied of being empowered to achieve their 'optimum health' (Ruger 2009). When low-quality water results in waterborne diseases and affects some groups or individuals more than others, it com- 
promises their normal health functionings, restricts their health choices and hampers their abilities to pursue health and life goals. In short, their health capability is affected by the differential availability, supply, quality and use of water. As stated earlier, considering the linkage between water availability and capability, this thesis borrows the social justice framework of $\mathrm{HCP}$, which gives due incorporating to life, health, determinants of health, and proposes human development as a whole, incorporating the biological dispositions, intermediate social contexts, the condition of the public health and healthcare system, and macro social, political, and environmental contexts (Ruger 2009).

(2) Lack of accessibility to quality water often results in waterborne diseases. It also affects the lives of women and children more than others by affecting their health, hygiene, sanitation, drinking capacity and water seeking behavior. From a health capability perspective, making provisions for good quality water to all is a public health obligation. Failure to do so leads to a failure of provision for ensuring and enabling an environment for all to be healthy. Considering this failure of obligation, this study makes an endeavor to have its foundation on the HCP. According to $\mathrm{HCP}$, the deprivations from achieving health are unjust, as they unnecessarily reduce the capability for health functioning, and especially affect the central health capability adversely.

(3) Since water is the major determinant of health, countries' water-related systems must offer individuals the desired amount of water for a healthy life, and its distribution should be equitable enough to conform to high-quality standards. Society, through the government, should guarantee equal access to appropriate water-related preventive measures, to an extent that prevents unwarranted and avoidable diseases and death. However, both legislature and the people must have a mutual commitment to accomplish a specific level of wellbeing by tending to the determinant of water. Through the HCP perspective, individuals, providers and institutions should work together to empower individuals and create a positive environment for all to be healthy by making high-quality water available, accessible, and utilizable by all. A schematic representation shows how water affects health capabilities of groups and individuals (Fig. 1).

With regards to Indian water-related activities, an absence of commitment to address these issues of water-related human health capability have been observed. As these failures are the scope within which inequalities can slip through, this paper, with its foundation on $\mathrm{HCP}$, puts forward the following recommendations.

\section{RECOMMENDATIONS}

(1) The Water Policy of India should consider having an underlying vision of health, specifically health as capability. Because health, when conceived as a capability, draws attention to its underlying determinants such as water, whose availability and accessibility affects the abilities of humans to be healthy. It also implies that the right to water is considered an integral part of human rights in water policy to ensure freedom from escapable and avoidable disease and death that arise from water-related issues. Consideration of the right to water in such means might help people to exercise their right to life - not just in gaining access to available water but also in the provision of measures to protect waterborne diseases.

(2) The IWMS in India should adopt an approach to go beyond its focus on making water available and accessible to all. In other words, IWMS, by going beyond its institutional approach within the water sector, should also collaborate with the health sector to give focus to waterborne diseases and the health inequity arising out of water issues. It implies that while health is to be a focus for the water sector, availability, accessibility, use and management of water need to be a focus for the health sector as well. This

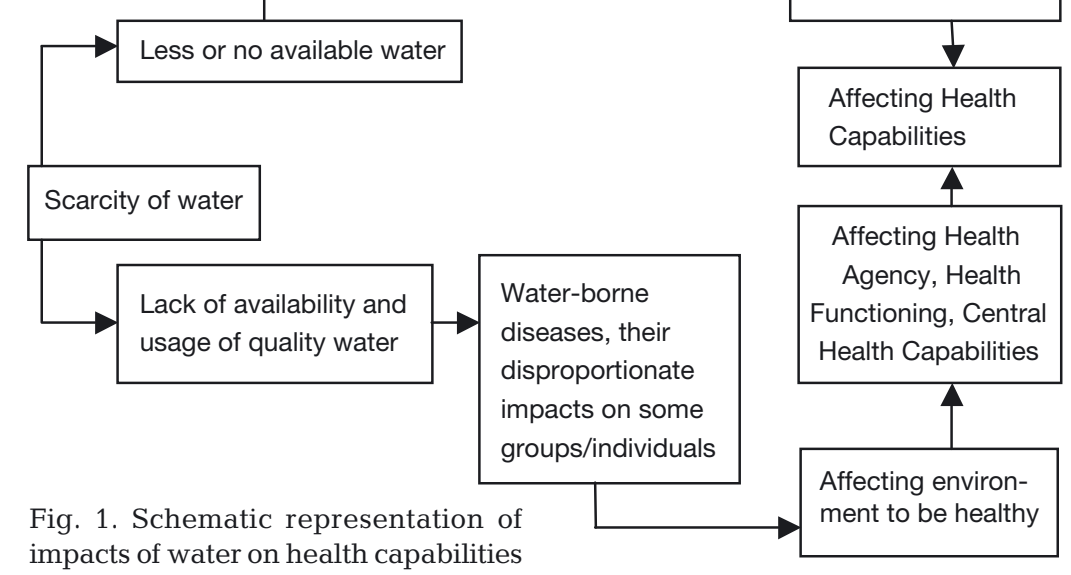


involves making people aware of the total amount of water available as a natural common asset in the locality and the long-term benefits to their health from the influence of water, as well as the need for good collaboration between healthcare workers and public health engineering departments in monitoring the quality as well as the use of water resources.

(3) The Indian National Water Mission, rather than focusing only on the physical feature and availability of water, should re-focus on how water affects the lives and health of groups and individuals differently. This implies not just participatory decision making and planning, but also getting feedback on how the local water resources are used, preserved and managed by the citizens; focusing more on those areas falling short of reaching actual health due to the lack of access to safe water. In short, the Indian Water Mission should execute its actions to create ethical places enabling all to use safe water and enabling all to be healthy by eliminating water as the source of disease and death.

(4) The CGWB of India should focus on shared health governance. That is, it should focus on the governance of water with shared responsibilities between public institutions, private agencies, environmental agencies and with collaboration between the health sector and public health departments, cooperation between the ground level healthcare workers such as Anganwadi workers and public health engineers, and with local people. It also implies educating people on the proportionate use of water and preventing misuse of water, empowering people to work on the prevalent water-related norms in the society, and enabling them to exercise their agencies for the right to water for health capabilities.

(5) Based on shared health governance, the Indian water policy should aim for efficient and effective use and management of water. This implies that Indian water policy should also aim to implement universal water coverage via shared costs and risk pooling. That is, identifying the areas lagging behind in access to water and mapping those areas where groups and individuals succumb as a result of access to unclean and contaminated water. Water policy should opt for implementing an integrated water care system funded through community-rating and progressive financing. With a community rating, everyone pays equally; with progressive financing, the wealthy are obliged to pay more taxes to choose a sustainable and effective watercare system. Water, no matter how it is distributed and accessed, is after all a natural element, which affects each and everyone in the world in some way or another, and some groups more than others.

\section{CONCLUSIONS}

This paper argues for the need for ethics in water management and use policies. It considers the fair provision of equitable protection of central health capability (that is, from escapable diseases and premature death caused by water-related issues) as one of the foremost and crucial reasons for more ethical water management policies. Using the social justice conceptual framework of the HCP, this paper explores how water, as a determinant of health capability, is connected to the health of people in different ways, and justifies the HCP in the discourse on water ethics by pointing out possible sources of disparities through the lapses and failures of policies in India. The paper has chosen the HCP for this purpose because the paradigm, through its concern for health capability, acknowledges and addresses the health problems that arise at the confluence of health and water. With a focus on India, this paper highlights the drawbacks of water-related initiatives, and argues that extending the equitable protection of water-related health capability is not adequately addressed in current Indian water policy. It further argues that water policy in India can benefit from Jennifer Prah Ruger's (2009) theory of 'Health Capability', especially by borrowing the guiding vision of 'health as a capability', to make a fair provision of equitable protection of central health capability impacted by unfair access, availability and usage of water.

Acknowledgements. The author acknowledges the opinions and comments of the 2 reviewers which helped the manuscript to refine its argument. The author is also indebted to the editor and his editorial team for editing the manuscript. The author also conveys a heartfelt gratitude to Prof. Darryl Macer under whose expert guidance this paper has become a comprehensive journal paper from a Masters thesis.

\section{LITERATURE CITED}

Acreman M (2004) Water and ecology. Series on water and ethics, essay 8. UNESCO, Paris

Anand PB (2013) Access to water and the capability approach. In: Water and capabilities. Maitreyee e-bulletin of the Human Development \& Capability Association, Brewster, MA, p 10-13

Asthana V, Shukla AC (2014) Water security in India: hope, despair, and the challenges of human development. Bloomsbury Publishing, New York, NY

Biswas AK (2008) Integrated water resource management: Is it working? Water Res Dev 24:5-22

Biswas AK, Tortajada C (2010) Future water governance: problems and perspectives. Int J Water Resour Dev 26: $129-139$ 
CGWB (Central Ground Water Board) (2015) Induction material of Central Ground Water Board. CGWB, Faridabad

Chakraborty D, Mukhopadhyay K (2014) Water pollution and abatement policy in India: a study from an economic perspective. Global Issues in Water Policy No. 10, Springer, Dordrecht

CMD (Comprehensive Mission Document) (2011) National water mission under national action plan on climate change. CMD, Delhi

FAO (2016) AQUASTAT. www.fao.org/nr/water/aquastat/ countries_regions/Profile_segments/IND-EnvHea_eng. stm (accessed 5 Apr 2016)

George RM (2012) Common property resources and human rights: politics of water struggles in India. New Century Publications, New Delhi

Government of India (2012) National water policy. Government of India, New Delhi

Government of India (2014) National vector borne disease control program (NVBDCP). Annual Report 2014-15. Government of India, New Delhi

Groenfeldt D (2010) Viewpoint - The next nexus? Environmental ethics, water policies, and climate change. Water Altern 3:575-586

HRWS (Human Rights to Water and Sanitation) (2016) Historical judgment on the right to water in India. Information Portal. www.righttowater.info/historical-judgementon-the-right-to-water-in-india/ (accessed 2 Jul 2016)

India Water Portal (2008) Water conflicts. http://conflicts. indiawaterportal.org/node/121 (accessed 14 Sep 2017)

Johnston BR, Hiwasaki L, Klaver IJ, Ramos Castillo AR, Strang V (eds) (2012) Water, cultural diversity, and global environmental change: Emerging trends, sustainable futures? UNESCO, Jakarta

Liu J, Dorjderem A, Fu J, Lei and others (2011) Water ethics and water resource management. Ethics and climate change in Asia and the Pacific (ECCAP) project, Working Group 14 Report. UNESCO, Bangkok

Macer D (1994) Bioethics, water, and the environment. Mer (Paris) 32:103-106

Menon MS (2016) Make the link: inter-linking of rivers holds the key to addressing water scarcity. http://indian express.com/article/opinion/columns/india-water-crisisdrought-marathwada-latur-water-train-2771756/ (accessed 4 May 2016)

MWR (Ministry of Water Resources, River Development and Ganga Rejuvenation), Government of India (2014a) Annual report 2014-15. Government of India, New Delhi

MWR (Ministry of Water Resources, River Development and Ganga Rejuvenation), Government of India (2014b) National water mission. http://wrmin.nic.in/forms/list.aspx? lid=267 (accessed 14 Sep 2017)

Mohan V (2016) 116 farmer suicides in first 3 months of $2016 \mathrm{http} / / /$ timesofindia.indiatimes.com/india/116-farmersuicides-in-first-3-months-of-2016/articleshow/52002524 .cms (accessed 4 May 2016)

Planning Commission (2013) $12^{\text {th }}$ five year plan. The Government of India, New Delhi. http://planningcommission.

Editorial responsibility: Darryl Macer,

Prakanon, Bangkok, Thailand nic.in/plans/planrel/fiveyr/default.html (accessed 21 Aug 2014)

Prüss-Üstün A, Corvalán C 82006) Preventing disease through healthy environments. Towards an estimate of the environmental burden of disease. World Health Organization, Geneva

* PTI (Press Trust of India) (2015) Dalits in MP village not allowed to use public borewell. http://timesofindia.indiatimes.com/india/Dalits-in-MP-village-not-allowed-to-usepublic-borewell/articleshow/47398037.cms (accessed 5 May 2016)

Rodda A (1991) Women and the environment. Zed Books, London

Ruger JP (2009) Health and social justice. Oxford University Press, Oxford

Seckler D, Barker R, Amarasinghe U (1999) Water scarcity in the twenty-first century. Int J Water Resour Dev 15:29-42

Selborne L (2000) The ethics of freshwater use: a survey. UNESCO, Paris

Tiwari A (2016) Drought-hit India needs a water-sensitive food trade policy. www.dailyo.in/business/drought-watercrisis-india-food-trade-policy-csir-yangtze-three-gorgesdam/story/1/10300.html (accessed 4 May 2016)

Venkatraman T (2015) Mumbai: water cuts to continue till 2016 due to poor monsoons. http://indianexpress.com/ article/cities/mumbai/mumbai-water-cuts-to-continuetill-2016-due-to-poor-monsoon/

Victor BI (2006) India: from alienation to an empowered community - applying a gender mainstreaming approach to a sanitation project, Tamil Nadu. In: Gender, water and sanitation case studies on best practices. United Nations, New York, NY, p 21-22

Water Ethics Network (2015) Exploring the ethics of water decisions. http://waterethics.org/the-water-ethics-charter/ (accessed 5 Apr 2016)

Water.org (2017a) Fundraiser overview. http://give.water. org/fundraiser/4967/ (accessed 12 Oct 2017)

Water.org (2017b) India. https://water.org/our-impact/india/ (accessed 3 Mar 2016)

WWater and Sanitation Program (2007) Water, sanitation, and hygiene for people living with HIV and AIDS. www. wsp.org/sites/wsp.org/files/publications/72200723130_ SAHIVAIDSFN.pdf (accessed 3 May 2016)

WHO (World Health Organization) (2015) WHO media center fact sheet: trachoma. www.who.int/mediacentre/factsheets/fs382/en/ (accessed 29 Jun 2016)

*WHO (2016a) WHO media center fact sheet: drinking water. www.who.int/mediacentre/factsheets/fs391/en/ (accessed 25 Apr 2016)

*WHO (2016b) Global health observatory (GHO) data: cholera. www.who.int/gho/epidemic_diseases/cholera/en/ (accessed 5 Jul 2016)

Wutich A (2013) Water insecurity, emotional distress, and mental illness: implications for human development \& capabilities. In: Water and capabilities. Maitreyee e-bulletin of the Human Development \& Capability Association, Brewster, MA, p 14-16

Submitted: September 12, 2016; Accepted: June 9, 2017

Proofs received from author(s): September 18, 2017 